\title{
LA IMPORTANCIA DE INTEGRAR LA DIMENSIÓN EMOCIONAL EN LA FORMACIÓN Y DESEMPEÑO DOCENTE
}

\author{
THE IMPORTANCE OF INTEGRATING THE EMOTIONAL \\ DIMENSION IN TEACHER TRAINING AND PERFORMANCE
}

\author{
Bernarda Toledo Toledo ${ }^{1}$ \\ Universidad Central, Chile
}

\section{Resumen}

En este artículo se formula una reflexión acerca del reconocimiento de la importancia de incorporar explícitamente el tema de las emociones en los ambientes donde se educan niñas, niños y jóvenes, de manera que los procesos formativos en la escuela sean instancias significativas que respondan a la comprensión del sentido de la integralidad humana, tanto del sujeto que aprende como del que enseña. Se propone hacerlo profundizando en las capacidades de escucha, confianza y la emoción de la alegría. Una parte importante de este trabajo se nutre de los referentes conceptuales de una tesis doctoral, un estudio hermenéutico que indaga en el lenguaje de las emociones en profesores de cuatro universidades chilenas.

\section{Palabras clave}

Emociones, educación, escucha, confianza, alegría.

1 bernarda.toledo@ucentral.cl

\begin{abstract}
This article reflects on the recognition of the importance of explicitly incorporating the issue of emotions into the environments where children and young people are educated, so that the training processes in school are instances respond to an understanding of the meaning of human integrality, from the learner's point of view as well as the one who teaches. It intends to do so by delving into the listening skills, confidence and emotion of joy. An important part of this work is nourished by the conceptual references of a doctoral thesis, a hermeneutic study that investigates the language of emotions in professors from four Chilean universities.
\end{abstract}

\section{Keywords}

Emotions, education, listening, trust, joy. 
Bernarda Toledo Toledo | La importancia de integrar la dimensión EMOCIONAL EN LA FORMACIÓN Y DESEMPEÑO DOCENTE

\section{INTRODUCCIÓN}

En las últimas décadas, las emociones están siendo objeto de estudio en múltiples disciplinas como la filosofía, la antropología, la lingüística, la biología, la sociología; también la psicología en todas sus ramas y, últimamente, las neurociencias, que han señalado el papel fundamental de las emociones en relación con la actividad de la conciencia y la mente, a partir de la investigación sobre el funcionamiento del cerebro humano. De todos estos conocimientos se debe sustentar la educación, con el propósito de recuperar el lugar y la importancia que tienen las emociones en los procesos de enseñanza-aprendizaje, así como en la labor formativa que les compete a los docentes y a todos quienes están vinculados al ámbito de la educación en los distintos niveles de escolaridad.

Este artículo pretende ser una propuesta que lleve a descubrir y a reflexionar en torno a la importancia de incorporar explícitamente esta dimensión emocional en los ambientes donde se educan niños, nińas y jóvenes, de manera que los procesos formativos sean realmente instancias que respondan a la comprensión de sentido de totalidad, tanto del sujeto que aprende como del que enseña. La educación religiosa tiene un rol clave en estos procesos, puesto que es un ámbito que busca conectar a la persona con la dimensión trascendente, de manera que progresivamente se desarrolle humana y espiritualmente.

Los temas desarrollados en las siguientes páginas se nutren de los elementos conceptuales de la investigación de la tesis doctoral de la autora (Toledo, 2018), un estudio hermenéutico sobre el lenguaje de las emociones en profesores de cuatro universidades chilenas. Para el propósito de este artículo, se toman algunos antecedentes de dicho estudio que dan cuenta de las dificultades pedagógicas que surgen cuando las emociones son invisibilizadas, así como la necesidad de integrar esta dimensión en el desempeño docente, puesto que hasta hoy los énfasis de las políticas educativas expresadas en el currículo aún están puestos en la razón, o dimensión intelectual, por sobre la emocional o afectiva. Luego, se exponen algunos desarrollos teóricos 
sobre la emoción humana de manera de verificar, por un lado, la existencia de conocimiento sobre el tema y, por otro, evidenciar la solidez que ya tiene este constructo.

Finalmente, y como resultado del análisis y del trabajo hermenéutico, se ofrece uno de los temas conclusivos de la investigación, que resulta plenamente pertinente para distintos contextos educativos que se considere; se trata de la escucha y la confianza. De ambas capacidades emergen una multiplicidad de emociones fundamentales para la educación integral de las personas. La reflexión acerca de la escucha y la confianza se articulará con una de las emociones básicas abordada por S.S. Francisco en su exhortación apostólica Evangelii gaudium (2013): la alegría cristiana.

A modo de conclusión, quedarán abiertas algunas interrogantes que invitan a continuar indagando y reflexionando, especialmente acerca de los beneficios que reporta transitar de manera consciente hacia las emociones que nos ofrecen bienestar, motivación y mayor conexión con uno mismo, con los otros, con el entorno y con Dios.

\section{Algunos antecedentes Que justifican el ESTUDIO Y VISIBILIZACIÓN DE LAS EMOCIONES EN LA FORMACIÓN Y DESEMPEÑO DOCENTE}

Todos quienes tienen experiencia docente se han encontrado con estudiantes enfrentados a una multiplicidad de situaciones con un marcado trasfondo emocional, como estar enfadados por resultados académicos deficientes, conflictos con los pares y con los profesores, estar bajo el estrés o la angustia; todas situaciones que directa o indirectamente inciden en el clima del aula y en las interacciones de manera significativa. Estos y otros muchos acontecimientos que ocurren cotidianamente en las salas de clases, así como fuera de ellas, son indicios de la importancia de incorporar la dimensión emocional en la formación docente. 
Bernarda Toledo Toledo | La importancia de integrar la dimensión EMOCIONAL EN LA FORMACIÓN Y DESEMPEÑO DOCENTE

Reconocer que los profesores son los actores clave en la generación de los cambios profundos que requiere la educación no significa que estén realmente capacitados para lograrlo, puesto que, más allá de contar con las competencias disciplinarias propias que les son exigidas, es fundamental declarar la importancia de que cuenten también con competencias socioemocionales. Estas competencias son las que, entre otros propósitos, pueden llevar a fomentar y fortalecer en la escuela relaciones armónicas, respetuosas, tolerantes, a crear climas de aprendizajes afectivos y efectivos, sanos y seguros con sentido de corresponsabilidad, interés por el cuidado del entorno, de sí mismos y de los demás, y estimular habilidades para enfrentar y superar conflictos y fracasos.

Cuando no se cuenta con el conocimiento ni las habilidades para conducir situaciones tan propias de las salas de clases, como sostener la motivación para el aprendizaje, crear experiencias de trabajo grupal positivas, establecer una comunicación emocional fluida y equilibrada, o encauzar las dificultades que se generan en la diversidad de las interacciones, la convivencia y el clima propicio para aprender se entorpecen y la calidad de los procesos de aprendizaje se debilita.

Ahora bien, en la línea de antecedentes vale la pena subrayar algunos hitos que obligan a examinar cuán necesario es el desarrollo de las competencias emocionales en los docentes. Uno de los más importantes está asociado al tema de la convivencia, al buen vivir, que se encuentra declarado en el Informe de la Comisión Internacional sobre la Educación para el siglo XXI, a la UNESCO, en el documento titulado La educación encierra un tesoro (Delors, 1996). En él se establecen los cuatro pilares fundamentales de la educación, siendo uno de ellos el "aprender a vivir juntos, aprender a vivir con los demás" (p. 103). Se trata de un factor educativo que presenta una estrecha conexión con la dimensión social y emocional, pues aprender a vivir juntos implica, cómo bien lo señala el documento, considerar que la educación tiene dos orientaciones complementarias. "En un primer nivel, el descubrimiento gradual del otro. En el segundo, y durante toda la vida, la participación en proyectos comunes, un método 
quizás eficaz para evitar o resolver los conflictos latentes" (p. 104). Para ambas orientaciones es clave la educación emocional, ya que en el caso de los conflictos interpersonales está probado que estos se desencadenan cuando emociones como la ira, la frustración, el odio, la intolerancia no se han encauzado apropiadamente.

En Chile, en el Marco para la Buena Enseńanza (MINEDUC, 2003) los dominios B (Creación de un ambiente propicio para el aprendizaje) y D (Responsabilidades profesionales) señalan algunos criterios que admiten explícita e implícitamente el aprendizaje de capacidades que se relacionan con la dimensión emocional y el aprender a vivir juntos. Así es como se espera que un profesor o profesora en el ejercicio de su rol docente, según el Criterio B.1: "Establece un clima de relaciones de aceptación, equidad, confianza, solidaridad y respeto (p. 13); Criterio D.4: "Propicia relaciones de colaboración y respeto con los padres y apoderados" (p. 15), es decir, se busca el desarrollo de las habilidades sociales y emocionales que contribuyen a la promoción de relaciones más estables y armoniosas en los espacios educativos. Respecto de estos criterios y de su relación con la dimensión social y emocional cabe preguntarse: ¿`cuándo y cómo los profesores desarrollan estas competencias? ¿Qué sentido les dan los docentes a las emociones en el espacio escolar? ¿Son capaces de hacer una lectura de sus propias emociones y de las de sus estudiantes?

Más recientemente, en los Estándares Orientadores para las Carreras de Pedagogía en Educación Básica (MINEDUC, 2011) y Educación Media (MINEDUC, 2012), se presentan los estándares pedagógicos, algunos de los cuales suponen exigencias formativas vinculadas a las competencias emocionales y sociales. Por ejemplo: "Está preparado para promover el desarrollo personal y social de los estudiantes" (E2); "Está preparado para gestionar la clase y crear un ambiente apropiado para el aprendizaje, según contexto" (E5); "Está preparado para atender la diversidad y promover la integración en el aula" (E8). Estos concuerdan con la idea que sostiene Casassus (2008) de que la enseñanza no es una técnica sino una relación, y que el aprendizaje ocurre en la relación; pensamiento muy similar defienden 
Bernarda Toledo Toledo | La importancia de integrar la dimensión EMOCIONAL EN LA FORMACIÓN Y DESEMPEÑO DOCENTE

Maturana y Dávila (2006): "La educación como un fenómeno de transformación en la convivencia es un ámbito relacional en donde el educando no aprende una temática, sino un vivir y un convivir. Aprende una forma de vivir el ser humano" (p. 32).

$\mathrm{Si}$ se consideran otros antecedentes, en Chile existe una Política Nacional de Convivencia Escolar desde el año 2002, cuya última versión corresponde a 2019. En ella se manifiesta la preocupación fundamental por alcanzar una sana convivencia escolar sustentada en el respeto, el buen trato, la participación y las formas pacíficas de enfrentar la violencia y los conflictos. Esta política se fundamenta, además, en un marco normativo que se ha ido construyendo a propósito de las dificultades que se han presentado en los contextos escolares; tres de los más importantes son la Ley N²0.536 sobre violencia escolar, promulgada en 2011; la Ley N²0.609 contra la discriminación, promulgada en 2012, y la Ley No20.845 de inclusión escolar, promulgada en 2015. Llevar adelante las exigencias que suponen tanto la Política Nacional de Convivencia Escolar como el cuerpo normativo supone el proceso de desaprender los actuales modos de relación y convivencia, para reaprender a construir comunidad. En este sentido, la educación religiosa puede aportar de manera sustantiva a la recuperación del reconocimiento de la dignidad de las personas y el sentido profundo que tiene el concepto de comunidad.

Por último, si se toma en cuenta el ámbito de la salud y el bienestar de los profesores, resulta aún más urgente integrar el mundo de las emociones en la formación de los docentes. Estudios como el de la UNESCO (2005), AA.VV. (2003) de la Pontificia Universidad Católica de Chile y el de Cornejo (2008), indican que las enfermedades de mayor frecuencia entre los profesores se relacionan con "problemas de salud mental", como la depresión y los trastornos de ansiedad; también los llamados malestares psicológicos, como el estrés y el síndrome de Burnout. Extremera y Fernández-Berrocal (2004) sostienen que el desarrollo de las habilidades de inteligencia emocional en los docentes tendría un carácter preventivo frente a estas enfermedades, principalmente el estrés: 
"[...] la capacidad para razonar sobre nuestras emociones, percibirlas y comprenderlas, como habilidad intrínseca del ser humano, implica, en último término, el desarrollo de procesos de regulación emocional que ayudarían a moderar y prevenir los efectos negativos del estrés docente a los que los profesores están expuestos diariamente” (p. 4).

Goleman (2013), por su parte, también hace referencia a esta situación, señalando:

"[...] un grupo numeroso se encuentra atascado en un estado que los neurobiólogos denominan 'desgaste', en el que la tensión constante sobrecarga su sistema nervioso con un gran caudal de cortisol y adrenalina. En lugar de fijar la atención en el trabajo, la dirigen a sus preocupaciones. Este agotamiento emocional puede conducir a la frustración y la apatía” (p. 34).

Ante este escenario, autores como Goleman (1997), Bisquerra (2005) y Fernández-Berrocal y Ruiz (2008), entre otros, coinciden en afirmar que, cuando se desarrolla la inteligencia emocional y las competencias emocionales, las personas se benefician en diversos aspectos de su vida laboral y personal, pudiendo observarse, además, que un aumento en el desarrollo de las habilidades sociales disminuye el abuso de drogas; que al incrementar la autoimagen positiva, aumenta el éxito académico; que al reducir comportamientos antisociales, mejora la salud mental y aumentan los comportamientos prosociales; todo lo cual redunda en que las personas pueden acceder a más y mejores experiencias de bienestar.

Ahora bien, si estamos de acuerdo con Larrosa (2007) en afirmar que la educación tiene que ver con la vida, con ganas de hacer vivir, con estimular el despertar a la vida, será necesario entonces disponer de las mejores condiciones, tanto en talento humano como en recursos materiales, que permitan a las personas desarrollarse plenamente en comunidad y ser felices. Uno de los caminos que podría orientar hacia esa meta es poner la mirada en los profesores, también sujetos de aprendizaje, quienes han de descubrir y promover la necesidad 
de transformar sus prácticas educativas en experiencias y espacios que comuniquen y contagien el gusto por desarrollarse en todas las dimensiones del ser humano (mente, cuerpo, espíritu). De este modo, las personas estarían en condiciones de descubrir el enorme potencial que poseen y las infinitas posibilidades de crecimiento que pueden alcanzar.

Es fundamental, entonces, devolverle a la escuela y a todo espacio educativo el sentido original y vital que posee, el lugar que acoge a los que vienen al mundo, seres únicos, originales, irrepetibles, personas que traen algo nuevo que aportar (Larrosa, 2006). Al adoptar esta visión de la escuela se integra y se vive la presencia de cada persona como riqueza, así como sus modos de interactuar, de compartir, de crear, entre tantas otras expresiones de cada ser humano. Es un espacio donde cobran valor los afectos y las emociones y, desde ellas y con ellas, se reflexiona, se piensa, se razona. En la escuela, los niños, niñas y jóvenes deben encontrar ese lugar junto a las personas que les ayuden a desplegar todo el potencial que poseen a fin de que puedan encaminar los sueńos que tienen para sus vidas.

\section{IMPORTANCIA Y SIGNIFICADO DE LAS EMOCIONES PARA EL DESARROLLO HUMANO INTEGRAL}

Todo lo que constituye la vida, lo que se ve, se piensa, se hace, huele y escucha; todo aquello que es posible conocer, está atravesado por las emociones, o tiene un filtro emocional que viene del cerebro (Mora, 2013). Ya no se sostiene una separación entre las emociones y la razón. Las emociones tienen poder, se pueden vivir con intensidades y duraciones diferentes según cómo se configure el mundo interno con la realidad o las situaciones externas. Cuando se es consciente de este poder, se puede hacer un trabajo personal en términos del aprendizaje que todas las emociones brindan; cuando ese poder se escapa y no se tienen herramientas para identificarlas, comprenderlas, 
regularlas y modificarlas, devienen los conflictos, frustraciones, culpas, agresiones.

Con estas palabras se introduce este apartado que busca exponer la construcción teórica sobre las emociones aportadas por tres investigaciones referenciales en este campo.

El concepto de "emoción" surgió hacia fines del siglo XIX; antes de este período se hablaba de pasiones, sentimientos, afectos, sensaciones (Belli, 2009, p. 34). La palabra "emoción" proviene del latín emotio, nombre que se deriva del verbo emovere, que significa movimiento o impulso; es decir, todo sentimiento que mueve hacia un pensamiento, una acción que puede ser positiva, destructiva o neutra; e-moción es energía en movimiento.

Sobre la teoría de las emociones se presentan tres perspectivas de investigadores acreditados. Una es la de Juan Casassus, filósofo y sociólogo chileno; otra es de Antonio Damasio, médico y neurólogo de origen portugués; y la perspectiva de Humberto Maturana, biólogo, docente e investigador chileno. Se eligió a estos autores, primero, porque representan diferentes disciplinas de estudio que permiten una mirada complementaria e interdisciplinaria; segundo, los tres investigadores inician su trabajo en las dos últimas décadas del siglo pasado y se encuentran plenamente vigentes hoy; en el estudio de las emociones son referentes de consulta connotados. Y por último, a pesar de la diversidad de sus enfoques ofrecen un común consenso respecto del reconocimiento de las emociones como un fenómeno importante para el desarrollo de la persona y unas fundamentaciones filosófica, biológica y/o psicológica sólidas. Es necesario señalar, naturalmente, que la selección de estos autores no excluye otras investigaciones y enfoques que están aportando valioso conocimiento en el campo de las emociones.

En la obra de Juan Casassus (2006) se encuentra un vasto estudio del mundo de las emociones y del estado en que se encuentra su desarrollo (2015, p. 101). Señala que la biología, la bioquímica y la neurología han investigado el modo en que las emociones se encarnan en el cuerpo; la psicología lo ha hecho para conocer la influencia de 
las emociones en las personas y en sus historias de vida, así como la sociología ha estudiado su influencia en sus aspectos relacionales.

Después de hacer un recorrido por temas como el cuerpo, la mente, la conciencia, el autor llega hasta la noción de emoción, señalando que las personas son "seres emocionales". Desde esta premisa desarrolla su propuesta sobre la emoción, las competencias emocionales y la educación emocional. Define las emociones como "un flujo de energía encarnada de carácter relacional y que contiene información” (2015, p. 98).

El autor integra el concepto de energía para explicar la emoción, y hace alusión a los múltiples significados que esta palabra tiene en la vida cotidiana, entendiéndola como "fuerza", la fuerza del calor, la fuerza del movimiento, la fuerza de la energía eléctrica, entre otras, para finalmente quedarse con la metáfora de la energía eléctrica y su paso a través del cableado. De modo similar, las emociones pasan por el sistema nervioso del sujeto, en el que también habría un flujo energético que sale fuera de él, generando así una conexión de lo interno con lo externo.

Para Casassus (2015) hablar de emociones es hacer referencia a diversos estados, experiencias y vivencias, las que se pueden identificar como alegría, asombro, admiración, celos, entre muchas otras. Al mismo tiempo, sostiene que todas ellas se vivencian en el cuerpo, en el mundo subjetivo, que a veces se las puede nombrar y que en otras ocasiones no se encuentran palabras para poder identificarlas y verbalizarlas (p. 99).

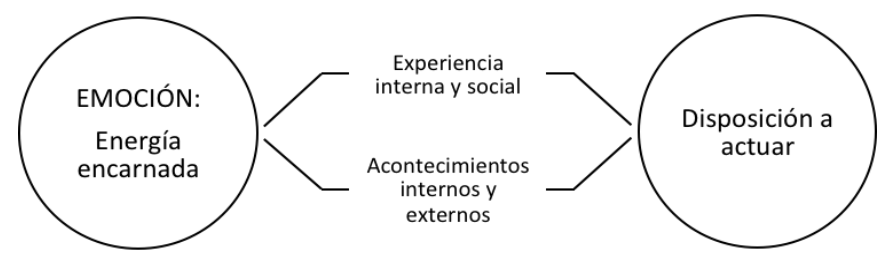

Figura 1. Representación del concepto de "emoción", según J. Casassus (2015, p. 99). Elaboración propia 
También propone un acercamiento a la comprensión de las emociones recurriendo a la noción de exploración. Afirma que las emociones se exploran mediante dos procesos; uno de ellos es el desarrollo de la conciencia emocional, mediante el cual se realiza la exploración interna; al otro proceso lo denomina comprensión emocional, a través del cual se exploran las interacciones emocionales con los objetos externos (Casassus, 2015).

$\mathrm{Su}$ perspectiva en ambientes educativos es muy iluminadora, ya que se enfoca en la importancia que tiene la incorporación de la educación del ser emocional en los contextos educativos formales y, por ende, en la preparación de los docentes. Dicha formación no puede ser abordada en momentos puntuales, sino como acción permanente que debería durar toda la vida. La actuación docente encierra en sí todo un mundo de proyecciones.

"Al enseñar, el docente proyecta sus pensamientos, sus experiencias y sus conocimientos, irradiando desde su cuerpo sus emociones en acciones, actitudes y tonalidades. A través de ellas, el docente entusiasma o aburre, se acerca o se distancia, crea confianza o desconfianza" (Casassus, 2008, p. 92).

Antonio Damasio, por su parte, desarrolla una amplia y consistente relación entre los descubrimientos sobre las emociones con postulados derivados de la filosofía. En sus principales obras (1994, 2000, 2007, 2010) aborda lo que para él es uno de los grandes problemas que enfrenta el estudio de la emoción y tiene que ver con la distinción entre emoción y sentimiento. En este sentido elabora claras diferenciaciones, afirmando que "las emociones se representan en el teatro del cuerpo y los sentimientos en el teatro de la mente" (Damasio, 2007). Por otra parte, vislumbra un problema que dice relación con la heterogeneidad de fenómenos que se califican de emocionales (2010, p. 174). De las emociones señala que:

“... son programas complejos de acciones, en amplia medida automáticos, confeccionados por la evolución. Las acciones se complementan con 
Bernarda Toledo Toledo | La importancia de integrar la dimensión EMOCIONAL EN LA FORMACIÓN Y DESEMPEÑO DOCENTE

un programa cognitivo que incluye ciertas ideas y modos de cognición, pero el mundo de las emociones es en amplia medida un mundo de acciones que se llevan a cabo en nuestros cuerpos, desde las expresiones faciales y las posturas, hasta los cambios en las vísceras y el medio interno" (p. 175).

Además, elabora una serie de constructos y teorías asociados a las emociones, como su estructura y funciones biológicas, su inducción, su mecánica (Damasio, 2000, pp. 67-79) y categorías (Damasio, 2007, pp. 46-54), destacando la gran relevancia que los conceptos de emoción y sentimiento tienen en la investigación neurobiológica actual.

La emoción, según Damasio (2007), constituye un complejo proceso que llega hasta el sentimiento; la primera constituiría la parte del proceso que se hace pública (cuerpo) y la segunda parte permanece privada (mente). El autor afirma que primero tenemos emociones y después sentimientos, ya que de este modo se ordenaron en el proceso evolutivo; las emociones son reacciones simples que promueven la supervivencia de los organismos (p. 34). Señala que las emociones son percepciones que se acompańan de ideas y modos de pensamiento, en contraste con los sentimientos, que se caracterizan por ser principalmente percepciones de lo que nuestro cuerpo hace mientras se manifiesta una emoción (2010, p. 176).

Damasio (2010) se refiere a la expresión o modulación de las emociones, indicando que, si bien se asemejan unas a otras, no son del todo iguales; la modulación se irá personalizando y asumirá características de acuerdo al grupo social donde se expresen las emociones; las expresiones emocionales pueden ser manifestadas a voluntad, pero no pueden ir más allá de las manifestaciones externas. Lo cierto es que la emoción tiene un mundo subjetivo interno que no se puede conocer del todo por las expresiones externas de esa misma emoción; el autor lo explicita con el siguiente ejemplo: "Cuando nos encontramos con un individuo estoico que tensa su labio superior cuando se entera de una trágica noticia, no suponemos que no sienta angustia o miedo" (p. 197). 
Por último, subraya la importancia del estudio de las emociones para el logro del bienestar de las personas, situando la discusión a un nivel más amplio y global.

"La comprensión de la neurobiología de la emoción y los sentimientos es clave para la formulación de principios y políticas capaces tanto de reducir las aflicciones como de aumentar la prosperidad de las personas. Efectivamente, el nuevo conocimiento se refiere incluso a la manera en que los seres humanos tratan tensiones no resueltas entre las interpretaciones sagradas y seculares de su propia existencia” (Damasio, 2007, p. 14).
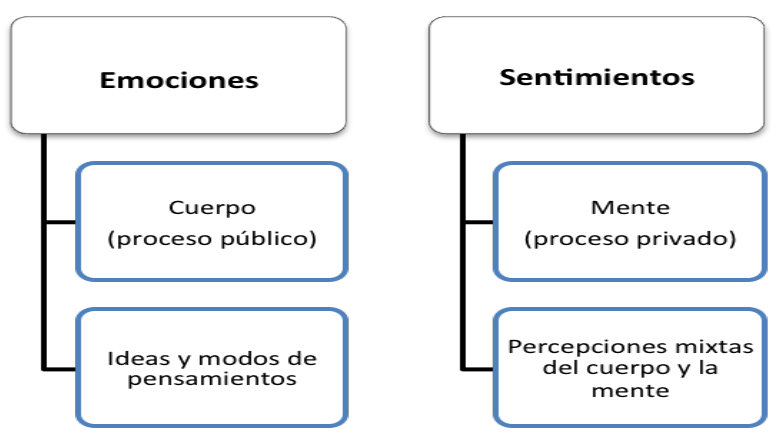

Figura 2. Representación de los conceptos de emociones y sentimientos de A. Damasio (2010, pp. 175. 185). Elaboración propia.

Finalmente, la tercera perspectiva es la de Humberto Maturana, cuyos aportes provienen del campo de la biología en estrecha conexión con el lenguaje. Su perspectiva tiene total vigencia, siendo un sólido referente en diversas disciplinas y contextos.

Para este autor, todo quehacer humano se fundamenta en una emoción que se da con el lenguaje; nada de lo propiamente humano se constituye sin este "entrelazamiento entre emoción y lenguaje" (2001, p. 65). Asegura que las emociones existen en la relación, no en el cuerpo, aunque estas se realizan a través de él (Maturana y Bloch, 1996, p. 29). De este dinamismo humano que 
es el emocionar y el lenguajear surge la convivencia humana, que él denomina como la aceptación del otro junto a uno.

Desde el punto de vista biológico, señala que las emociones "son disposiciones corporales dinámicas que definen los distintos dominios de acción en que nos movemos. Cuando uno cambia de emoción, cambia de dominio de acción" (2001, p. 8).

El biólogo se refiere al fenómeno del emocionar como otro constructo clave en la comprensión de la biología de las emociones.

"Yo llamo emocionar al fluir de una emoción a otra en el fluir del vivir. En el emocionar la dinámica relacional del ser vivo cambia al cambiar la configuración de su dinámica estructural interna, y este cambio cambia el ámbito de sus haceres posibles" (Maturana y Bloch, 1996, p. 43).

Es decir, el emocionar ocurre cuando cambiamos de dominio de acciones, y eso ocurre cuando pasamos de una emoción a otra. Luego, agrega: "Si puedes ver el emocionar de un ser vivo en su ámbito de existencia, podrás saber cómo vive y, al revés, si sabes cómo vive, podrás inferir su emocionar" (Maturana y Bloch, 1996, p. 43).

Para Maturana el emocionar y las emociones son ámbitos que no se pueden desprender de la realidad propiamente humana: "Todo el vivir animal, en general, y el vivir humano en particular, ocurre desde el emocionar. Las emociones constituyen el fundamento de todo lo que hacemos, incluso el razonar" (1996, p. 91).

En el desarrollo de su teoría sobre el emocionar, Maturana vuelve una y otra vez sobre la importancia de comprender este fenómeno, y lo hace recurriendo a la vivencia cotidiana, especialmente cuando se hace alusión al "emocionarse"; el término apropiado es "conmoverse". Su análisis surge de la falta de conciencia acerca de que todo el vivir es desde el emocionar.

En su teoría de las emociones, Maturana (1996) también realiza una distinción entre emoción y sentimiento; las emociones no se expresan, sino que se viven; por tanto, lo que se expresa es el sentir o sentimiento. El sentimiento es la apreciación que se hace sobre cómo está otro o como estamos nosotros en relación con el emocionar, es 
decir, cómo nos encontramos en un dominio de acción o ámbito relacional. Desde su perspectiva, el sentimiento supone el lenguaje, puesto que este surge de la reflexión que se hace sobre el emocionar del otro o de uno mismo; en cambio, la existencia de las emociones no necesita del lenguaje.

"Las emociones no requieren del lenguaje para ocurrir. Los sentimientos, en cambio, corresponden a distinciones reflexivas que hacemos en el lenguajear sobre cómo estamos, o nos parece que está el otro, en el emocionar $y$, por tanto, requieren del lenguaje en su existir" (Maturana y Bloch, 1996, p. 247).

Finalmente, es importante subrayar la indisoluble relación que se da entre razón y emoción que propone Maturana. Lo primero es el reconocimiento de la sobrevaloración que la cultura le otorga a la razón, bajo el supuesto de que es la dimensión que diferencia a los seres humanos de los otros seres del mundo animal; por ende, desde allí viene la desvalorización de las emociones (2001, pp. 35-65). Desde su perspectiva, todo sistema racional tiene un fundamento emocional. Considera que no es la razón la que lleva a la acción, sino la emoción. "El vivir humano es emocional y racional a la vez, siempre, no lo uno o lo otro. [...] Por esto, al cambiar nuestra emoción, cambia nuestro razonar, y cambian nuestro ser y nuestro mundo" (Maturana y Bloch, 1996, p. 171).

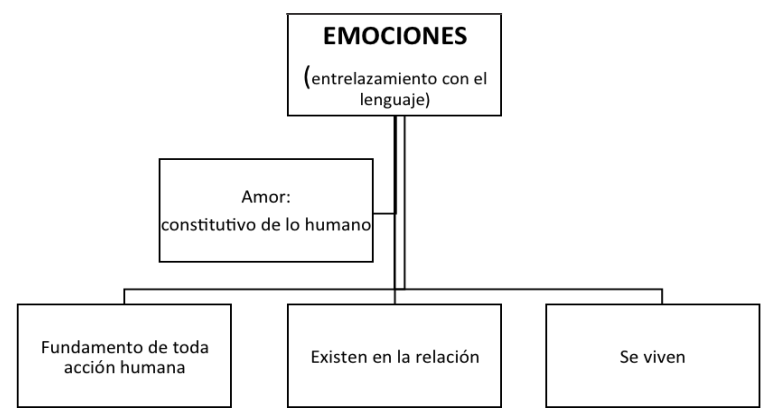

Figura 5. Representación del significado de emociones de Humberto Maturana (2001). Elaboración propia. 
Observando estas tres perspectivas acerca del estudio de las emociones se puede constatar que todos intentan aportar conocimiento en pos de mejorar la vida y el desarrollo de las personas, puesto que, en general, las conclusiones dicen relación con que el ser humano puede alcanzar un mayor bienestar cuando es consciente de su capacidad para encauzar sus emociones de manera positiva.

Las emociones impactan la historia y las historias personales llevando a actuar en determinadas direcciones, a tomar decisiones, se esté o no consciente de ellas. De ahí la necesidad de introducir el conocimiento de esta dimensión humana entre quienes tienen un rol educativo, pues son sujetos que están en diálogo permanente con sus estudiantes, consigo mismos, con el entorno; y en ese dialogar se experimentan y se comunican emociones. Es relevante contribuir a que se establezcan las relaciones necesarias entre las emociones y aquellos objetivos que las personas se proponen en la vida, de modo de contar con los recursos para modularlas de la mejor manera, y así decidir las situaciones en las que emplear mejor la energía y las capacidades.

Sin embargo, pese al avance que están aportando las investigaciones sobre este campo, de los innumerables relatos y experiencias acumulados, aún persiste una concepción peyorativa cuando se habla de emociones; se las reprime, minimiza, controlan, se silencian. Cuando se consideran las apreciaciones académicas sobre el valor de las dimensiones afectivas o emocionales, se reconoce su escasa valoración sociocultural y formativa; la escuela, por ejemplo, todavía se inclina preferentemente hacia aquello que se piensa y se razona por sobre lo que se siente; los énfasis en los procesos de enseñanzaaprendizaje se ponen en los contenidos conceptuales y escasamente en los actitudinales y socioemocionales. Estamos de acuerdo con Casassus cuando afirma:

"Nadie nos enseña el lenguaje para hablar de lo interno y subjetivo. Nadie nos enseńa más que lo que pienso, sin embargo, soy lo que 
siento. Antes de existir porque pienso (según el famoso cogito ergo sum de Descartes), yo existo porque siento" (2017, p. 122).

Es importante volver a subrayar que todos quienes tienen una tarea en la formación de personas son agentes primordiales que deben orientar sus acciones hacia el máximo desarrollo del potencial que cada sujeto posee, situación que ocurre cuando se reconoce a los estudiantes como seres integrales, es decir, personas que se incorporan al mundo con capacidad para sentir (emoción), pensar (razón) y hacer (acción).

Re-conocer las emociones, es decir, identificarlas, modularlas, comprenderlas y regularlas puede aportar a un cambio cultural que permita ayudar a entender que las personas son artífices de sus propias vidas, tanto individual como comunitariamente.

Considerando este núcleo teórico sobre las emociones, se abren interesantes oportunidades a la educación religiosa, puesto que desde ese lugar se puede generar y al mismo tiempo fortalecer la convicción y necesidad de ser capaces de construir proyectos de vida cada vez más humanizadores, que impacten positiva y constructivamente en las personas, en el entorno y en las comunidades. Cuando se conoce en profundidad la realidad del ser humano, adquiere mayor sentido su conexión con el mundo, con la cultura, consigo mismo y con su dimensión espiritual, que está entretejida de emociones.

\section{UNA PROPUESTA PARA INTEGRAR LA DIMENSIÓN EMOCIONAL EN LA FORMACIÓN Y DESEMPEÑO DOCENTE: DESDE LA ESCUCHA, LA CONFIANZA Y LA EMOCIÓN DE LA ALEGRÍA}

A partir de los referentes teóricos anteriormente expuestos, es posible afirmar con certeza que las emociones movilizan al ser humano a actuar en la vida imprimiendo en la experiencia características personales que están fuertemente determinadas por la naturaleza 
de las mismas. La gran gama de emociones ${ }^{2}$ que se vivencian en la cotidianidad puede impulsar a la renovación, la transformación y el crecimiento, pero también puede llevar al aislamiento, al conflicto, a las relaciones tóxicas. Por ende, toda acción que tienda a iluminar, orientar y acompañar a las personas, principalmente cuando las emociones del miedo, la tristeza y la rabia consumen la existencia, favorecen la posibilidad de incorporar la energía necesaria que proviene de las emociones positivas, las que ayudan al bienestar personal, como el entusiasmo, la serenidad, la gratitud, el asombro, el interés, la alegría.

Cuando los seres humanos ya no escuchan, cuando pierden la confianza, y cuando se aleja la alegría, los grupos y las personas pueden dañar su brújula, es decir, su horizonte de sentido. No está de más recordar que el ser humano es un ser que se constituye como tal en las relaciones que establece desde que nace y a lo largo de toda su vida; en esta dinámica relacional se entrelazan emociones, pensamientos, sentimientos y acciones que le permiten desarrollarse y evolucionar.

En razón de lo anterior, se hablará de la escucha, la confianza y la alegría como instancias actitudinales y emocionales que fundan una propuesta para realizar el proceso de integración de la dimensión emocional en la formación y desempeño docentes.

La "escucha” y la "confianza" son capacidades humanas recíprocas que están sostenidas por múltiples emociones que disponen de manera constructiva a las personas a los procesos de cambio. Se comprende la escucha como la actitud que otorga sentido y valor a la presencia del otro; no solo se trata de un acto de comunicación, sino sobre todo de apertura y comprensión, a través del habla, a toda la complejidad del otro. Casassus (2015), citando a Max van Manen, realiza una interesante conexión entre escucha docente y aprendizaje.

2 Según Punset y Bisquerra (2015), existen trescientas siete emociones, las que tienen distintas intensidades y relaciones entre sí. Sin embargo, también afirman que las personas no experimentan normalmente más de treinta emociones. 
"[...] el aprendizaje ocurre cuando el profesor tiene la capacidad sensible de 'interpretar los pensamientos internos, comprensiones, emociones y deseos de los niños a partir de pistas indirectas, tales como las actitudes, gestos, expresiones y lenguaje corporal'. Cuando un docente ha desarrollado esta competencia de escucha y de lectura de sus alumnos, entonces él o ella sabe cuándo y cómo incluir el proceso de aprendizaje en los alumnos" (p. 254).

Es justamente esa actitud de escucha la que se reconoce como primordial en los educadores: la capacidad de leer más allá de las palabras, "oír más que interpretar", según Ríos (2006). La escucha es un acto que ocurre en cada persona; es necesario "escucharse", de manera que se esté capacitado para escuchar desde una posición amplia, atento con todos los sentidos al "habla" del otro.

En el acto de escucha se pueden reconocer tres movimientos: escucharse, escuchar y sentirse escuchado (Ríos, 2013, p. 124). "El acto de escucha reclama, pues, alguien que hable, alguien que escuche y un contexto que posibilite la acción" (p. 125).

Desde la escucha se pueden crear lugares de reflexión, de relaciones horizontales, de espacios y tiempos que cobran sentido nuevo. Asimismo, a partir de la escucha tienen lugar la apertura a lo diverso, la creatividad y la autonomía; la escucha genera un ambiente relacional abierto, que encanta y al mismo tiempo integra las emociones, disponiendo a la transformación, al aprendizaje.

La escucha y la confianza son disposiciones y actos que se reclaman simultáneamente en los contextos educativos, y son indispensables para mirar a la persona que hay detrás de cada estudiante, de cada profesor, sujetos que se pierden y desdibujan entre las exigencias, rigideces y tecnicismos del sistema educativo, situación que puede dificultar la atención a las emociones que emanan de estas actitudes, como la serenidad, amabilidad, atención, paciencia, disfrute, acogida, aceptación, entre tantas otras.

En cuanto el aprendizaje se desarrolla a partir de las relaciones que se construyen entre un profesor y sus estudiantes, el acto de escucha y la confianza entre ambos sujetos resulta clave para que 
Bernarda Toledo Toledo | La importancia de integrar la dimensión EMOCIONAL EN LA FORMACIÓN Y DESEMPEÑO DOCENTE

efectivamente se dé esta dinámica de interacciones más constructivas. Casassus (2008) se refiere a este aspecto cuando expone el concepto de "conexión".

"[...] una competencia (del docente) por la cual el otro (el alumno) siente que es visto, escuchado y aceptado, sin juicio ni crítica, por lo que ese otro es. En la conexión hay confianza y seguridad, y el buen clima se basa precisamente en la existencia de confianza y seguridad. Ambas son emociones que hacen posible el aprendizaje" (p. 90).

La escucha profunda se sostiene en la confianza, de modo que confiar viene a ser otro acto fundamental para construir relaciones que favorezcan el desarrollo integral y el bienestar de las personas, grupos, comunidades, a fin de colaborar en el desarrollo de sociedades más solidarias y fraternas. Sin embargo, es posible visualizar sus oponentes (falta de escucha y desconfianza), pues son muchas las ocasiones en que la actitud primera hacia las personas es la desconfianza.

En el actual contexto sociocultural, se observan notorias desconfianzas tanto en ambientes públicos como privados; se ha naturalizado la suspicacia ante todo y ante todos, y el hecho de que se observen frecuentemente relaciones en que priman la deslealtad, el poder y la competencia debilita el valor de la confianza en el otro. En muchos ambientes es probable que las personas tiendan al aislamiento y la pérdida de conciencia del valor intrínseco de los otros y de sí mismos. De ahí la urgencia por recrear espacios de convivencia que estén sustentados en relaciones de respeto, de escucha, confianza y reconocimiento.

Desde otro punto de vista, se considera muy necesario el cultivo y la restitución de la escucha y la confianza para realizar procesos formativos con un enfoque humanizador, es decir, otorgar la posibilidad de que la formación se oriente hacia perfiles docentes de mayor complejidad, donde los profesores tengan la capacidad para crear espacios relacionales transformadores que integren el lenguaje de las emociones y que motiven desde esta dimensión de la persona la manifestación de la riqueza humana. 
Se trata de abrirse y disponerse a la creación de una nueva cultura de aula, donde la relación profesor-estudiante se establezca desde la cercanía; una relación que no excluye la dimensión intelectual; por el contrario, la enriquece y la fecunda afectando al sujeto y movilizándolo a ser co-constructor de su propio proceso formativo.

"Amar a un ser humano es brindarle la oportunidad de ser escuchado con profunda atención, interés y respeto; aceptar su experiencia sin pretender modificarla, sino comprenderla; ofrecerle un espacio en el que pueda descubrirse sin miedo a ser calificado, en el que sienta la confianza de abrirse sin ser forzado a revelar aquello que considera privado" (Maturana, 2008).

Finalmente, la emoción de la alegría. ¿Por qué subrayar principalmente esta emoción y toda la variedad de emociones que se relacionan con ella? Porque desde hace algunos años se observan con más frecuencia situaciones sociales y culturales, acontecimientos y experiencias que están enquistando odio, rabia, tristeza, decepción, frustración, emociones que se contagian y aumentan. S.S. Francisco (2013) observa esta realidad desde la perspectiva de los desafíos que presenta el mundo actual. "La alegría de vivir frecuentemente se apaga, la falta de respeto y la violencia crecen, la inequidad es cada vez más patente. Hay que luchar para vivir $y$, a menudo, para vivir con poca dignidad" ( $\left.\mathrm{N}^{\circ} 52\right)$.

Entonces aparecen la pregunta: ¿quién enseña a mirar las emociones, a reconocerlas e iniciar el camino de superación, de expansión del corazón hacia experiencias de alegría y júbilo? Nadie puede negar que la alegría es la emoción que devuelve la esperanza; es una emoción capaz de transformar y poner en el punto de partida de un nuevo nacimiento.

La alegría es una emoción primaria o básica; en esto coinciden algunos autores (Casassus, 2015; Damasio, 2007; Goleman, 1997), al igual que la ira, el miedo y la tristeza. Estas cuatro emociones "presentan ciertos patrones de reacción afectiva distintivos, generalizados y que suelen mostrar una serie de características comunes en todos los seres 
Bernarda Toledo Toledo | La importancia de integrar la dimensión EMOCIONAL EN LA FORMACIÓN Y DESEMPEÑO DOCENTE

humanos" (Choliz, 2005, p. 9); tienen componentes fisiológicos claros y evidentes, principalmente en las expresiones faciales (Casassus, 2015, p. 109). También son consideradas como emociones primarias el amor, la vergüenza, la culpa, la envidia, la sorpresa y el asco. Existen también las secundarias, constituidas por emociones derivadas de las emociones primarias. Por ejemplo, en el caso de la rabia es posible identificar emociones como: agresión, enojo, ira, furia, odio, cólera, irritación, disgusto, exasperación. Y en relación con la alegría, pueden reconocerse: júbilo, contento, entusiasmo, buen humor, placer, dicha, diversión, optimismo, regocijo, gratificación, entre otras.

La alegría junto con el amor y la felicidad son reconocidas por Punset y Bisquerra (2015) como una de las familias de emociones positivas o luminosas. Para estos autores, la alegría es la emoción que se produce ante un suceso favorable. Las principales causas de alegría son: el logro de objetivos, relaciones con los amigos, satisfacciones básicas (comer, beber, gratificación sexual), experiencias exitosas, superar un examen, conseguir un empleo, curarse de una enfermedad grave, ir de vacaciones, finalizar con éxito unos estudios, cobrar algún dinero, entre otras.

La alegría es una emoción que, junto con aquellas que la secundan, han inspirado la exhortación apostólica Evangelii gaudium (La alegría del Evangelio) del papa Francisco (2013), que se ha considerado importante incorporar a esta reflexión. En los primeros párrafos de este documento, S.S. Francisco realiza una reflexión personal acompańada de fundamentos bíblicos; se puede observar la recurrencia de la palabra alegría y sus diferentes formas verbales: alégrate, alegre, alegró, alegrará, alegraron; también recurre a emociones secundarias de la alegría, como gozo, júbilo, dicha, entusiasmo, regocijo, exulta y feliz.

Cuando S.S. Francisco nombra la alegría y sus emociones secundarias, lo hace subrayando el dinamismo y la energía que surgen de estas. La mayoría de las veces se orientan a indicar el poder de estas emociones para el cambio y la transformación personal y del mundo; por ejemplo, la alegría "nace y renace" $\left(\mathrm{n}^{\circ} 1\right)$; en el primer 
título la alegría se "renueva y comunica". El Papa pone el centro de esta emoción en la persona de Jesús, de quien proviene y a quien se dirige la alegría.

En los ocho primeros párrafos, la mayor parte de las veces se encuentra la palabra alegría junto a otros conceptos, lo que da la impresión de que se la quiere exaltar, que por sí misma es insuficiente para expresar lo que provoca o provocará en aquellos que la hagan nacer en su corazón, y se aplica tanto a las palabras del Papa como a los textos bíblicos que utiliza. Algunos ejemplos de este uso son "multiplicaste la alegría" (N4); "grita de alegría" ( $\left.N^{\circ} 4\right)$, "cantos de alegría" ( $\left.\mathrm{N}^{\circ} 4\right)$; "estremece de alegría" ( $\left.\mathrm{N}^{\circ} 5\right)$; "engendrar la alegría" $\left(\mathrm{N}^{\circ} 7\right)$; "genuina alegría" ( $\left.\mathrm{N}^{\circ} 7\right)$.

Con este mensaje, S.S. Francisco hace un llamado y una invitación a las personas y a los cristianos en el contexto de la auténtica vivencia de plenitud (en la alegría) que constituye esencialmente el evangelio de Jesús, trascendiendo esa seriedad formal de las estructuras rituales que des-emocionalizan la consustancial alegría de la "buena noticia". En el documento se busca devolver el sentido humano de la fe, evidenciando su ausencia en una cultura que está subyugada a la emoción que se le opone, la tristeza. Es interesante develar esa dimensión humanizadora que entraña la alegría; cuando "nace, renace y se comunica", todo se ilumina, la esperanza se vuelve más cierta. Esta constatación debería ser muy incidente en toda práctica educativa, y especialmente en la enseñanza escolar de la religión.

Entonces, reconstruir la escucha, la confianza y la alegría es un desafío ineludible si se quieren recuperar y renovar los espacios educativos que aún permanecen disponibles para engendrar en las vidas de estudiantes y profesores el anhelo por una sociedad sustentada en el amor que Jesucristo encarna. La educación religiosa es una de las vías para retomar con nuevo sentido estas capacidades tan propiamente humanas. 
Bernarda Toledo Toledo | La importancia de integrar la dimensión EMOCIONAL EN LA FORMACIÓN Y DESEMPEÑO DOCENTE

\section{Conclusión}

Investigar y reflexionar en torno al mundo de las emociones es una tarea que está comenzando, especialmente en el ámbito de la educación religiosa; requiere poner atención e intención para realizar una aproximación más transparente y renovada.

El mundo de las emociones todavía está teñido de desconocimiento y prejuicios, de actitudes negativas y despectivas, barreras que es necesario derribar realizando estudios y procesos de reflexión sistemáticos y permanentes.

Son muchos los desafíos que es necesario asumir. Por una parte, conectar de manera más directa y contextualizada la dimensión emocional y la educación religiosa; lo que es válido para la educación general lo es también para la educación religiosa, pero a esta siempre se le exige más, dada la magnitud de su objetivo como es cultivar la dimensión trascendente y religiosa de niños y jóvenes. Por otra parte, las investigaciones que hemos revisado en este texto tienden reconcebir al ser humano primordialmente como un "ser emocional", e indican que las emociones son la energía vital que mueve a actuar (Casassus, 2015), y que cuando cambiamos de emoción cambiamos de acción (Maturana, 2001); entonces, es muy válido sostener que el resultado de cualquier acción o proceso de educativo estará fundado en la emoción; es decir, los resultados serán coherentes con las emociones que se generan antes, durante y después de dicho proceso.

Caben en este momento preguntas como: ¿los profesores son conscientes y/o conocen esta dinámica emocional que opera en las personas y que está presente en el aprendizaje de los estudiantes?; luego, ¿qué experiencias pedagógicas se han de promover para que los estudiantes sean conscientes, comprendan y sean capaces de gestionar sus emociones? ¿Qué acciones educativas pueden emprenderse para que estudiantes y profesores sean capaces de vivenciar una mayor gama de emociones, enriqueciendo así su experiencia vital? ¿Cómo hacer para darles el lugar y equilibrar estas dos grandes dimensiones 
del ser humano, razón y emoción, que, como señalan algunos de los investigadores y las neurociencias, están estrechamente vinculadas?

En consecuencia, queda mucho camino por recorrer, puesto que, mirar al ser humano desde su interioridad, explorar "lo que guarda más allá”, es una tarea que exige permanente formación y se requiere, ante todo, disponer el corazón y la mente a cambiar y crecer como persona y como profesional, día a día.

La invitación queda abierta para iniciar las búsquedas necesarias que permitan avanzar en la comprensión de la persona como un ser emocional y racional, un ser que piensa, siente y se expresa. Cuando hablamos de educar la dimensión religiosa, lo hacemos desde la convicción de que esta involucra a toda la persona, sin sesgos, considerándola un ser completo e inacabado al mismo tiempo; un ser inserto en el tiempo, en una cultura, un ser que está siempre en búsqueda de sentido y de trascendencia. La dimensión emocional, entonces, es una realidad sustantiva de la experiencia humana.

\section{REFERENCIAS BIBLIOGRÁFICAS}

AA.VV. (2003). Estudio de la salud laboral de los profesores en Chile. Facultad de Medicina y Ciencias Sociales. Pontificia Universidad Católica de Chile. Recuperado de: www.opech.cl/...Docente/ Estudio\%20de\%20Salud\%20Laboral\%20de\%20P...

Belli, S. (2009). Emociones y lenguaje (Tesis Doctoral). Departamento de Psicología Social. Universidad Autónoma de Barcelona. Recuperado de: www.tdx.cat/bitstream/handle/10803/5473/ sblde1.pdf?sequence $=1$

Bisquerra, R. (2005, 3 de diciembre). La educación emocional en la formación del profesorado. Revista Interuniversitaria de Formación de Profesorado. Recuperado de: http://www.redalyc.org/articulo. oa?id=27411927006 
Bernarda Toledo Toledo | La importancia de integrar la dimensión EMOCIONAL EN LA FORMACIÓN Y DESEMPEÑO DOCENTE

Casassus, J. (2015). La educación del ser emocional. $5^{\mathrm{a}}$ ed., Santiago, Chile: Cuarto Propio.

(2017, diciembre). Una introducción a la educación emocional. Revista Latinoamericana de Políticas y Administración de la Educación. RELAPAE. Recuperado de: http://relapae.com. ar/numero-7/

------- (2008, diciembre). Aprendizaje, emociones y clima de aula. Paulo Freire. Revista de Pedagogía Crítica. Recuperado de: http:// revistas.academia.cl/index.php/pfr/article/view/480

Cornejo, R. (2008, agosto). Entre el sufrimiento individual y los sentidos colectivos: Salud laboral docente y condiciones de trabajo. Revista Docencia. Recuperado de: http://revistadocencia. cl/-revist37/web/images/ediciones/Docencia_35.pdf

Damasio, A. (2000). Sentir lo que sucede. Cuerpo y emoción en la fábrica de la consciencia. Santiago, Chile: Andrés Bello.

- (2007). En busca de Spinoza. Neurobiología de las emociones y los sentimientos. (1 $1^{a}$ edición 2005). Barcelona, España: Crítica. (2010). Y el cerebro creó al hombre. ¿Cómo pudo el cerebro generar emociones, sentimientos, ideas y el yo? Barcelona, Espańa: Destino.

Delors, J. (1996). La educación encierra un tesoro. Informe a la Unesco de la Comisión Internacional de Educación para el Siglo XXI. Madrid, España: Santillana Ediciones UNESCO.

Extremera, N. y Fernández-Berrocal, P. (2004). La importancia de desarrollar la inteligencia emocional en el profesorado. Revista Iberoamericana de Educación. Recuperado de: www.rieoei.org/ deloslectores/759Extremera.PDF

Fernández-Berrocal, P. y Ruiz, D. (2008, 2 de septiembre). La inteligencia emocional en la educación. Electronic Journal of Research in Educational Psychology. Recuperado de: http://www. redalyc.org/html/2931/293121924009/ 
Freire, P. (2003). El grito manso. Buenos Aires, Argentina: Siglo XXI.

Goleman, D. (1997). La inteligencia emocional. Buenos Aires, Argentina: Javier Vergara Editor.

(2013). Focus. El motor oculto de la excelencia, Argentina S.A.: Ediciones B.

Larrosa, J. (2006). Sobre la experiencia. Aloma Revista de Psicología, Ciencias de la Educación y del Deporte. Universitat Ramon Llull. Recuperado de: www.raco.cat 2006: Núm.: 19 Larrosa Bondía. -------- (2007). Conferencia acerca de la experiencia. Recuperado de: https://youtu.be/k7OpdwOwaNY

Maturana, H. y Bloch, S. (1996). Biología del emocionar y Alba Emoting. Santiago, Chile: Dolmen Ediciones S.A.

Maturana, H. (2001). Emociones y lenguaje en educación y politica. 10a ed., (1990, 1a edición), Santiago, Chile: Dolmen Ediciones, S.A. Ensayo.

Maturana, H. y Dávila X. (2006). Biología del conocer y biología del amar. Desde la matriz biológica de la existencia humana. Revista PRELAC. Recuperado de: https://unesdoc.unesco.org/ ark:/48223/pf0000145502

MINEDUC (2003). Marco para la buena enseñanza, $1^{\text {a }}$ edición. CEIP, Santiago, Chile.

- (2011). Estándares orientadores para egresados de carreras de Pedagogía en Educación Básica. Estándares pedagógicos y disciplinarios. Santiago de Chile. Recuperado de: www.ceppe.cl/images/stories/ agenda/Estandares-basica-final.pdf

(2012). Estándares orientadores para carreras de Pedagogía en Educación Media. Estándares pedagógicos y disciplinarios. Santiago, Chile. Recuperado de: www.cpeip.cl/usuarios/cpeip/.../ librosestandaresvale/libromediafinal.pdf 
MINEDUC-DGE, (2019). Politica nacional de convivencia escolar. Santiago, Chile. Recuperado de: http://convivenciaescolar.mineduc. cl/politica-nacional-2/

Mora, F. (2013, enero-febrero). ¿Qué es una emoción? Arbor. Recuperado de: http://arbor.revistas.csic.es/index.php/arbor/ article/view/1543/1584

OREAL/UNESCO (2005, octubre). Condiciones de trabajo y salud docente. Estudio de casos en Argentina, Chile, Ecuador, México, Perú y Uruguay. Recuperado de: unesdoc.unesco.org/ images/0014/001425/142551s.pdf

Punset, E. y Bisquerra, R. (2015). Universo de emociones. Ver en www.universodeemociones.com.

Ríos, T. (2006). La comprensión del acto de escucha en la educación escolar a partir de la filosofía reflexiva de Paul Ricoeur. Revista Latinoamericana Polis. Recuperado de: https://polis.revues.org/4937

Ríos, T. (2013). La hermenéutica reflexiva en la investigación educacional y social. Manizales, Colombia: Centro de Publicaciones, Universidad de Manizales.

S.S. Francisco (2013). Evangelii gaudium. La alegría del evangelio. Recuperado de: https://www.aciprensa.com/Docum/ evangeliigaudium.pdf

Toledo, B. (2018). El lenguaje de las emociones en los formadores de profesores. Un estudio hermenéutico en cuatro universidades de la Región Metropolitana de Chile (Tesis doctoral). Facultad de Pedagogía. Universidad Academia de Humanismo Cristiano, Santiago, Chile.

Fecha de recepción: 15 de mayo de 2019

Fecha de aceptación: 28 de junio de 2019 